\title{
FORMAS DE DISCRIMINACIÓN EN EL CONSUMO, A LA LUZ DEL PRINCIPIO DE IGUALDAD Y NO DISCRIMINACIÓN ${ }^{1}$
}

\author{
Dulfay del Cristo Monsalve Muñoz ${ }^{2}$
}

\section{Resumen}

En Colombia, es común que productores y proveedores realicen actos discriminatorios injustificados en contra de consumidores. Esta es una realidad invisibilizada que merece atención del Estado y de particulares, debido a que su práctica genera lamentables consecuencias en los derechos fundamentales de las personas afectadas, situación inaceptable en un Estado Constitucional como el nuestro. En el presente trabajo, se analizan pronunciamientos de la Superintendencia de industria y comercio y de la Corte Constitucional de Colombia sobre discriminación de consumidores, lo que llevará a la clasificación de las formas en que este fenómeno se presenta en el país, y la precisión de sus elementos representativos.

Palabras Clave: Igualdad, consumidores, discriminación, acceso al consumo.

\section{Abstract}

In Colombia, the unjustified discrimination acts against consumers by producers and providers are common. This is an invisible reality that deserves attention from the State and private individuals, due to the unfortunate consequences for fundamental rights of the people affected, an inacceptable situation at a Constitutional State like ours. On the present work, pronouncements of the Superintendence of Industry and Commerce as

1 Informe de avance de la investigación "Igualdad y no discriminación de consumidores en Colombia: análisis desde su condición y tutela judicial efectiva", adelantada para la obtención del título de Magíster en Derecho, y desarrollada en el marco del Programa Colciencias Consuma Caribe 2015-2016.

${ }^{2}$ Abogada y Magister en Derecho de la Universidad de Cartagena. Docente adscrita al Centro de investigación sociojurídica de la Corporación Universitaria del Caribe-CECAR. Líder del semillero Derechos Humanos y posconflicto de la misma institución vinculado al grupo de investigación GISCER. Teléfono: 300-7097656. Email: dulfay.monsalvem@cecar.edu.co 


\section{Dulfay del Cristo Monsalve Muñoz}

well as the Constitutional Court of Colombia about consumer's discrimination are analyzed, this leads to classifying the ways this phenomenon is presented in this country and the accuracy of its representative elements.

Keywords: Equality, consumers, discrimination, consumption access.

\section{Introducción}

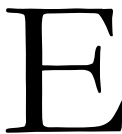

n el artículo 13 de la Constitución Política de Colombia se consagra la igualdad y no discriminación como un principio que irradia a todas las personas en el territorio, y que debe ser respetado, incluso, en relaciones comerciales particulares como las que se derivan de una relación de consumo. En armonía, la Ley 1480 de 2011 en su artículo tercero, numeral 1.12, estipuló la igualdad y no discriminación como un derecho de los consumidores. No obstante, es común que en nuestro país se manifiesten casos sobre discriminación de personas en disposición de entablar una relación de consumo, situaciones que generan la afectación de derechos fundamentales como la igualdad, la libertad y la dignidad humana, ya que colocan a los individuos discriminados en situación de desventaja respecto de sus semejantes.

En efecto, de acuerdo con el principio constitucional de igualdad y no discriminación, cualquier persona debe tener la posibilidad de acceder al consumo de bienes y servicios, cumpliendo con criterios objetivos de acceso, tal como el pago de un precio conforme al producto. En este sentido, cualidades como color de piel, orientación sexual, nacionalidad, situación de discapacidad, etc., no deben constituir criterios para discriminar a los consumidores.

Pues bien, en este escrito se realiza el examen de aquellas situaciones en las cuales una persona, en su condición de consumidora, resulta discriminada, lo que nos llevará a la caracterización de las formas de discriminación de consumidores que se presentan en Colombia, a la luz del principio de igualdad y no discriminación. Las anotaciones que se realizarán a continuación son producto de la exploración y el análisis de sentencias de la Corte Constitucional y de pronunciamientos de la Superintendencia de industria y comercio. 
Formas de discriminación en el consumo, a la luz del principio de igualdad

En suma, por medio del presente análisis se determinarán aspectos transversales, y se precisarán reglas de interpretación necesarias para la atención de las formas de discriminación en el consumo que fueron individualizadas.

\section{Metodología}

El presente escrito constituye un informe de avance de una investigación cualitativa, clasificada como jurídica - dogmática, cuya realización implica la recopilación y análisis de información secundaria, dentro de la cual se encuentran resoluciones y conceptos de la Superintendencia de industria y comercio, sentencias de la Corte Constitucional en sede de revisión de tutelas, así como doctrina y normatividad en torno al principio de igualdad y no discriminación y al Derecho del consumo.

El abordaje de la investigación se circunscribe a dar respuesta a la siguiente pregunta orientadora: ¿cuál es la relación jurídica del principio de igualdad y no discriminación respecto de la situación de los consumidores en Colombia, en consideración a su condición y tutela judicial efectiva? Para tales efectos, en este escrito se presentan de manera descriptiva las formas de discriminación en el consumo y los aspectos representativos de cada uno de ellos. Lo anterior, producto del análisis de las fuentes documentales emanadas de la Superintendencia de industria y comercio y dela Corte Constitucional de Colombia, organismos que se han pronunciado sobre el tema.

\section{Resultados}

Como resultado del análisis propuesto, fueron precisadas tres formas en las que los consumidores de bienes y servicios son discriminados, a saber: la aplicación de condiciones contractuales desiguales para operaciones equivalentes, la negación del acceso a un establecimiento de comercio abierto al público, y la negación a contratar con personas inmersas en cri- terios sospechosos de discriminación, cuya definición y aspectos generales representativos serán desarrollados a renglón seguido: 


\section{Discriminación de consumidores en la aplicación de condiciones contractuales desiguales para operaciones equivalentes}

Esta forma de discriminación en Colombia se encuentra prevista como acto de competencia desleal por abuso de posición dominante, así:

(...) cuando exista posición dominante, constituyen abuso de la misma las siguientes conductas: (...) 2. La aplicación de condiciones discriminatorias para operaciones equivalentes, que coloquen a un consumidor o proveedor en situación desventajosa frente a otro consumidor o proveedor de condiciones análogas (...). (Decreto 2153, 1992, art. 50)

En concordancia, es posible afirmar que dentro de esta clasificación se incluyen aquellas situaciones en las que el proveedor, distribuidor o comercializador, ofrece un producto con condiciones contractuales disímiles, respecto a las ofrecidas a otros clientes sin justificación alguna, colocando a unos consumidores en posición desventajosa respecto de aquellos que resultaron beneficiados, siendo que todos se encontrabanen igualdad de condiciones y se trataba de la misma operación comercial. La anterior definición se ofrece partiendo de que, "como regla básica en el mundo mercantil, la discriminación sólo existirá cuando, en igualdad de situaciones, se adopten conductas empresariales desiguales" (Porfirio, 2002, p. 77).

Se aclara que las implicaciones respecto a la discriminación de proveedores no serán revisadas en este trabajo; sólo aquellas atinentes a las condiciones de discriminación de consumidores que los coloquen en una situación desigual frente a otros en condiciones análogas.

Pues bien, la Superintendencia de Industria y comercio, organismo competente para la atención de este tipo de casos, estableció los siguientes elementos especiales para considerar configurada la conducta descrita en el numeral dos del artículo 50 del Decreto 2153 de 1992 antes transcrito:

i) Que se trate de operaciones equivalentes ii) Que el operador dominante aplique condiciones discriminatorias a dichas operaciones equivalentes iii) Que la aplicación de las condiciones dis- 
Formas de discriminación en el consumo, a la luz del principio de igualdad

criminatorias coloquen en situación desventajosa a consumidores o proveedores en condiciones análogas. (Superintendencia de Industria y comercio, Resolución 42828, 2010)

A continuación, procedemos al análisis de cada uno de estos elementos: Para determinar que efectivamente estamos frente a operaciones equivalentes, es primordial examinar el contexto en que se ofrece el producto, es decir, las circunstancias de tiempo, modo y lugar que rodean el negocio jurídico, aspectos que de alguna forma inciden en las condiciones contractuales. También deberán tenerse en cuenta circunstancias como las examinadas por la Superintendencia de industria y comercio en Resolución 42828 de 2010 (p.18-19). Esta entidad, respecto al cobro de valores diferentes para llamadas de móvil a fijo y viceversa, verificó la infraestructura empleada y los costos eficientes de las operaciones comerciales comparadas, concluyendo que estas configuran operaciones equivalentes.

En cuanto al segundo aspecto, esto es, la aplicación de condiciones discriminatorias en operaciones equivalentes, se precisa que consiste en el ofrecimiento de condiciones contractuales favorables a ciertos clientes sin justificación alguna, lo que genera una posición desventajosa respecto del consumidor en igualdad de condiciones que noes favorecido. Lo anterior encierra un efecto discriminatorio, ya que, “[...] en el momento de otorgar una condición comercial a determinada persona [o grupo de personas], de manera inmediata las personas [o grupos de personas] con igual característica adquieren el derecho de exigir un mismo comportamiento" (Velandia como es citado por Bernal, Botero \& Botero, 2011, p. 44). En este sentido, siempre que se trate de operaciones equivalentes, el proveedor, distribuidor o comercializador debe aplicar las mismas condiciones contractuales, pues, de no actuar de conformidad, podría incurrir en actuaciones discriminatorias en contra de los consumidores.

Dentro de las condiciones contractuales que podrían tener variaciones en perjuicio de los consumidores, se pueden destacar: la forma de pago, el precio, y el término para el cumplimiento de las obligaciones. Claro está, para su examen es necesario tener en cuenta el tipo de contrato celebrado, dado que, aunque se trate del mismo producto, sería irrazonable exigir al 
productor o proveedor la aplicación de condiciones análogas tratándose de negocios jurídicos diferentes.

En el mismo aparte antes transcrito, la Superintendencia de industria y comercio afirma que, para entender configurada la actuación prevista en el artículo 50 del Decreto 2153 de 1992, es necesario determinar que la aplicación de las condiciones discriminatorias sí coloque en situación desventajosa a los consumidores en condiciones análogas (Resolución 42828, 2010). De este requisito se deriva la necesidad de verificar que los consumidores involucrados en las operaciones comerciales comparadas se hallen en condiciones análogas y que, en efecto, por la aplicación injustificada de condiciones contractuales disímiles, se coloque en posición desventajosa a unos consumidores respecto de otros, aspectos que pasamos a analizar seguidamente:

Para determinar si los consumidores se hallan en condiciones iguales, es propio verificar que no se trate de aquellos contratos en los que las cualidades particulares del cliente pueden incidir en la creación de sus cláusulas, lo cual se considera conforme a la Constitución, siempre y cuando, para la variación de las cláusulas contractuales, no se empleen de manera injustificada cualidades susceptibles de ser catalogadas como sospechosas de discriminación.

Ejemplo de un acto jurídico cuyas cláusulas varían dependiendo de las cualidades especiales del cliente podría ser el contrato de seguros. En este se tienen en cuenta aspectos propios del consumidor para calcular el valor de la prima y estipular ciertas condiciones, aspectos que deberán ser sustentados objetivamente con estudios sobre valoración del riesgo.

Cabe resaltar que en otros países, como los pertenecientes a la Unión Europea, las compañías de seguro han sido llamadas a disminuir el empleo de este tipo de criterios para fijar las condiciones del contrato, porque se considera que, más allá de la objetividad del estudio sobre el cual se base, se trata de una discriminación con efectos negativos para un consumidor respecto del otro y, por tanto, se tienen por inconstitucionales (Tribunal de justicia Unión Europea, 2011).

Ahora bien, la labor de verificación de la existencia de condiciones análogas en que puedan encontrarse los consumidores inmersos en las 
operaciones objeto de comparación, se refiere a la constatación de aspectos externos al consumidor, pero que contribuyen a su categorización de manera objetiva, tales como los tenidos en cuenta por la Superintendencia de industria y Comercio en la resolución 42828 (2010, p. 27), es decir, las condiciones de demanda y el tráfico o volumen del uso del servicio, reflejado en la elasticidad del precio establecido en las operaciones comparadas.

Por último, será necesario constatar que la aplicación de condiciones desiguales para operaciones equivalentes sí genere una posición desventajosa para aquellos consumidores en condiciones análogas. Al respecto, es pertinente traer a colación los hechos estudiados por la Superintendencia de industria y comercio en la Resolución 04285 de 2002. En este caso, dejando de lado las implicaciones por competencia desleal derivadas del abuso de la posición dominante, es propio resaltar que SATENA, aerolínea que opera vuelos a municipios sin cobertura, fue sancionada por ofrecer, de manera injustificada, tarifas especiales con descuentos significativos a personas pertenecientes a un grupo religioso, a funcionarios públicos y personal militar. Ante la imposibilidad de SATENA de fundamentar su actuación, la Superintendencia de industria y comercio (2002) concluyó que se encontraba frente a una evidente discriminación, al colocar a unos consumidores en situación de desventaja, tratándose de clientes en condiciones análogas.

En todo caso, el proveedor del bien o servicio que aplique condiciones desiguales que resulten discriminatorias para los consumidores, deberá justificar ampliamente las medidas adoptadas y demostrar la objetividad de los criterios empleados para el ofrecimiento de las condiciones favorables a unos clientes respecto de otros. Lo anterior, por cuanto "la igualdad constitucional considera discriminatoria toda diferencia de trato (positiva o negativa) arbitraria, esto es, que no esté suficientemente justificada" (Díaz de Valdés, 2015, p. 163). Así pues, la justificación que pueda ofrecerse de parte del productor/ proveedor, constituirá la línea de separación entre un trato diferenciado y una discriminación propiamente dicha. 


\section{Discriminación de consumidores como negativa del acceso al esta- blecimiento}

El acceso a lugares públicos es reconocido en la Convención sobre la eli- minación de todas las formas de discriminación racial como un derecho derivado del respeto por el principio de igualdad y no discriminación, así:

...los Estados partes se comprometen a prohibir y eliminar la discriminación racial en todas sus formas y a garantizar el derecho de toda persona a la igualdad ante la ley, sin distinción de raza, color y origen nacional o étnico, particularmente en el goce de los derechos siguientes: (...)

f) El derecho de acceso a todos los lugares y servicios destinados al uso público, tales como los medios de transporte, hoteles, restaurantes, cafés, espectáculos y parques. (1965, art. 5)

Aunque en la citada convención, el derecho de acceso a lugares públicos se centre en la segregación de personas por motivos raciales, este se puede predicar de cualquier ser humano en virtud del ejercicio de sus libertades fundamentales. Puntualmente, el derecho de acceso a lugares públicos de- berá hacerse extensivo hacia aquellos motivos de exclusión que, al igual que la raza, son susceptibles de ser catalogados como sospechosos de dis- criminación, a saber: el sexo, el origen nacional o familiar, la lengua, la religión, la opinión política o filosófica (Const., 1991, art. 13), entre otros.

Así las cosas, se tiene que la discriminación como negación del acceso a un establecimiento podría definirse como la actuación ejercida por parte del productor y/o proveedor de bienes o servicios para impedir que una persona o grupo ingrese a un establecimiento de comercio, o para expulsarlos del mismo de manera arbitraria, con fundamento en prejuicios y estereotipos sociales injustificados, negando por tanto el acceso a losproductos ofrecidos.

Por supuesto, algunos de los afectados con actuaciones de este tipo, al ver vulnerado su derecho a la igualdad y su dignidad humana, han acudido a la acción de tutela; por ello la Corte Constitucional Colombiana en sede de revisión se ha referido al tema. Precisamente, producto de la exploración jurisprudencial realizada, fueron encontradas siete sentencias emitidas 
por esta colegiatura, T- 1090 de 2005, T- 131 del 2006, T- 909 de 2011, T314 de 2011, T-366 de 2013, T- 291 de 2016 y T-030 de 2017, y una sentencia de la Corte Suprema de Justicia Sala Penal, Sentencia No.38572 del 25 de septiembre de 2008, acción de tutela contra Café Bar Gavanna y Scirocco. La Corte Suprema de Justicia conoció del caso en virtud de la impugnación de un fallo de tutela que no amparó el derecho a la igualdad y no discriminación de los accionantes. De las sentencias antes mencionadas se pueden destacar las siguientes generalidades:

a) Del escenario de discriminación: Estos casos de discriminación se manifiestan al momento de acceder a los establecimientos de comercio o lugares destinados a la prestación de los servicios, por ejemplo, los mencionados en la Convención sobre la eliminación de toda forma de discriminación racial, es decir, medios de transporte, hoteles, restaurantes, cafés, espectáculos y parques (1965, art. 5), y se agregan otros lugares como "las discotecas, tabernas, bares u otros sitios de diversión nocturna" (Corte Constitucional de Colombia, T-1090, 2005).

Adicionalmente, al hablar de escenario de discriminación, la Corte Constitucional se refiere al contexto en que se desarrolla el acto, lo que no solo alude al lugar como tal, sino a otros aspectos trascendentales para establecer la intensidad de la afectación, tales como: la relación de poder, autoridad, sujeción o dependencia que exista entre la persona que se siente discriminada y la que lleva a cabo los actos de discriminación; el tipo de interacción que tiene lugar entre la persona afectada y quienes presencian los actos de discriminación, es decir, si entre el público que presencia la discriminación se encuentran familiares, amigos, compañeros de estudio o trabajo, lo cual acentúa los sentimientos de vergüenza y humillación producto de la discriminación; la libertad que tenga la persona afectada de abandonar el lugar en que se escenifica el acto discriminatorio, y las consecuencias de esa decisión, por ejemplo, un salón de clases, la cárcel, salón de juntas o lugar de trabajo, espacios en los cuales la persona necesita autorización para poder salir; la duración del acto discriminatorio; y, por último, si el actor de la discriminación tomó medidas correctivas, se retractó o reparó los perjuicios causados al afectado (Corte Constitucional de Colombia, T-141, 2015). 
b) Del agente discriminador: Como agente discriminador en la negación del acceso al establecimiento, se involucra el funcionario encargado de la seguridad o del control del ingreso, llámese portero, guardia de seguridad, vigilante, etc. Por lo general, estos manifiestan estar cumpliendo órdenes de sus superiores, es decir, de los representantes legales o propietarios de los establecimientos.

c) De las razones empleadas para el rechazo: Los establecimientos de comercio abiertos al público materializan el acto discriminatorio en la negativa del acceso al lugar, por medio del empleo de maniobras de rechazo que encubren la realidad de la discriminación que se realiza. Maniobras tales como la exigencia de carnet o reservación, la negación del ingreso por realización de evento privado, y la manifestación acerca del lleno a tope o falta de capacidad del lugar. En todo caso, el agente señalado de realizar el acto discriminatorio debe probar la causa alegada.

d) De las víctimas de los actos discriminatorios: En el tipo de discriminación de consumidores bajo análisis, la negación a una persona o grupo del acceso a un establecimiento coincide de manera sospechosa con la tenencia, por parte de los afectados, de cualidades sospechosas de discriminación. Por ello, en estos casos se configura la llamada presunción de discriminación que consiste en que, ante el rechazo de una persona que cuente con una cualidad sobre la cual se encuentra prohibido discriminar, se tendrá por cierto que fue realizado en razón de esa cualidad. Al respecto, el autor argentino Roberto Pablo Saba (2008, p. 698-699) afirma que calificar de sospechoso a un criterio de clasificación que se utilice como fundamento de un trato desigual es cubrirlo de una presunción de inconstitucionalidad, lo que invierte la carga argumentativa y probatoria en contra del señalado de violar el derecho a la igualdad, sea el Estado o un particular.

e) De los derechos vulnerados al consumidor discriminado: La Corte Constitucional ha considerado que, con los actos discriminatorios materializados en la negación del acceso a sitios abiertos al público, se vulneran los siguientes derechos: libre desarrollo de la personalidad, dignidad humana, honra, intimidad, y por supuesto, el derecho a la igualdad y no discriminación. No obstante, cabe agregar que con la negación del acceso a los establecimientos de comercio se vulneran también los derechos como 
consumidores, que se traducen en una necesidad insatisfecha y una expectativa de consumo incumplida.

f) De las órdenes impartidas en el fallo: En las sentencias estudiadas se ordenó la formación en Derechos Humanos y diversidad para representantes legales, socios y trabajadores. También se ordenaron visitas de inspección periódicas para verificar que no se siguieran cometiendo actos discriminatorios, labor encomendada a la Defensoría del pueblo (Corte Constitucional de Colombia, T- 1090, 2005). Además, se previno a los representantes legales para que en el futuro se abstuvieran de impedir el ingreso de cualquier persona a esos establecimientos en razón del criterio fundamento de la discriminación realizada. Igualmente, se ordenó a la Defensoría del pueblo, la Procuraduría y la Alcaldía del lugar, que tomaran las decisiones necesarias dentro de su competencia para evitar que los establecimientos demandados reincidieran (Corte Constitucional de Colombia, T131, 2006).

Adicionalmente, en la Sentencia T-909 de 2011, la Corte Constitucional ordenó a los representantes legales del centro comercial y de la empresa de vigilancia, actores de la discriminación, que presentaran excusa escrita y pública por haber expulsado del lugar a una pareja homosexual, así como también ordenó socializar el fallo con todos los trabajadores, contratistas y arrendatarios de los locales comerciales. Resulta pertinente mencionar que solamente en una de las sentencias halladas, la T-1090 de 2005, se condenó al pago de una indemnización por perjuicios morales causados, condena en abstracto por tratarse de una acción de tutela.

Todas las anteriores apreciaciones conforman las generalidades que se pueden derivar como resultado del análisis jurisprudencial propuesto. A continuación, antes de pasar al siguiente tipo de discriminación, se presentarán unas anotaciones sobre la discriminación de consumidores por negación tácita del acceso al establecimiento y sobre la reserva del derecho de admisión, aspectos trascendentales al hablar de la negación del acceso al establecimiento y los efectos que esta actuación puede generar sobre los derechos de los consumidores. 


\section{Discriminación de consumidores por negación tácita del acceso al establecimiento}

Otra forma de negación del acceso al establecimiento es aquella que se manifiesta de manera implícita al no ofrecer medios físicos para la inclusión de personas en condición de discapacidad. Es decir, el hecho de que un establecimiento de comercio no se encuentre adecuado estructuralmente para recibir a personas en sillas de ruedas, o no cuente con menús ni avisos adecuados para personas ciegas, entre otras posibilidades, es una forma de negar el acceso al consumo a las personas que así lo requieran.

Por ende, la diferencia con respecto a los demás casos analizados radica en que aquí la exclusión no se realiza de manera directa o mediante acciones, sino de manera tácita a través de la omisión de los propietarios de los establecimientos u organizadores de eventos, de adecuar las instalaciones para el acceso al consumo por parte de todas las personas sin importar sus cualidades diversas.

\section{Reserva del derecho de admisión vs Discriminación de consumidores}

Es pertinente mencionar que, en Colombia, algunos establecimientos abiertos al público seleccionan sus clientes escudándose en un pequeño cartel en la entrada del lugar que anuncia: nos reservamos el derecho de admisión. No obstante, en la exploración realizada no fueron encontradas sentencias de la Corte Constitucional al respecto, o que guardaran cercanía con el objeto de estudio de la presente investigación. Esto nos lleva a inferir que, tal vez, muchos de los consumidores rechazados en virtud de dichocartel no han acudido a instancias judiciales por concluir que la exposición del mismo autoriza al establecimiento a realizar exclusiones entre sus clientes de forma legítima.

Sin embargo, cabe aclarar que en nuestro país el mencionado derecho de admisión no se encuentra regulado. De hecho, como resultado de la exploración, se halló un proyecto de Acuerdo para el Concejo de Bogotá (2013), cuyo propósito es frenar los actos de discriminación en este tipo 
de establecimientos a través de la exposición al público de los criterios de acceso.

Pues bien, colocar un cartel con la leyenda: nos reservamos el derecho de admisión, y realizar exclusiones a partir de ella, se trata de una actuación arbitraria de los propietarios o administradores de los establecimientos abiertos al público. En otras palabras, Estos carteles no constituyen una autorización para discriminar, ya que "[1]a prevalencia de los derechos fundamentales, está por encima de cualquier disposición de naturaleza legal o reglamentaria" (Corte Constitucional de Colombia, T-808, 2003), por tanto, estos tendrán prevalencia en colisión con derechos como la autonomía privada o libertad negocial.

Dicho lo anterior, pasamos a la revisión de la última de las formas de discriminación en el consumo.

\section{Discriminación de consumidores como abstención de celebrar contratos}

Otra forma en la que se manifiesta la discriminación en el consumo es a través de la abstención, por parte de un productor o proveedor, de contratar con algunos consumidores. En estos casos, colisionan los derechos a la igualdad como no discriminación, y la dignidad humana del consumidor, con la autonomía contractual y la libertad de empresa del productor o distribuidor. Esta relación será estudiada en el presente acápite.

Siguiendo el orden empleado para explicar la discriminación de consumidores como negación del acceso al establecimiento, a continuación se presentarán las generalidades que se pueden sustraer del análisis de las sentencias T- 1165 de 2001, T- 1118 de 2002, T-763-05 y T- 140 de 2009, producto de la exploración jurisprudencial realizada sobre discriminación de consumidores como abstención de contratar. Se resalta que también se precisaron las sentencias T- 517 de 2006 y T-987 de 2012, en las que no fueron empleados criterios sospechosos de discriminación para la abstención a contratar.

Cabe anotar que esta última, es decir, la abstención de contratar, también se tiene estipulada como acto de competencia desleal por abuso de la 
posición dominante, por cuanto un empresario más poderoso en el mercado, se abstiene de ofrecer productos a otros empresarios, principalmente materias primas; actuación que afecta la producción de la parte discriminada. Sin embargo, estas implicaciones no serán objeto del presente estudio, pues extralimitarían el objeto de análisis establecido.

Hecha la anterior aclaración pasamos al estudio de las generalidades propuestas:

a) Del escenario de discriminación: Es importante aclarar que en este tipo de discriminación de consumidores, puede que la negación a celebrar el contrato se realice de manera presencial, en cuyo caso también aplicaría la verificación de los elementos para determinar la intensidad de la afectación que fueron explicados en el aparte de la discriminación como negativa de acceso al establecimiento. Nos referimos a la relación de poder que exista entre la persona que se siente discriminada y la que lleva a cabo los actos de discriminación; el tipo de interacción que tiene lugar entre la persona afectada y quienes presencian los actos de discriminación; la libertad que tenga la víctima de abandonar el lugar en que se escenifica el acto discriminatorio; la duración del acto discriminatorio; y, por último, si el actor de la discriminación tomó medidas correctivas, se retractó o reparó los perjuicios causados al afectado (Corte Constitucional de Colombia, T141, 2015).

Ahora bien, la abstención a contratar puede no manifestarse de manera presencial, caso en el cual, la comunicación de la abstención de contratar se realiza por escrito. Ante estas situaciones podría afirmarse que no existe un escenario de discriminación, ya que no está determinado un lugar para escenificar el rechazo, ni hay testigos presenciales como lo serían los acompañantes cuando la abstención a contratar o la negación del acceso al establecimiento se realiza presencialmente.

b) Del agente discriminador: Cualquier productor o proveedor podría convertirse en sujeto activo de la discriminación de consumidores como abstención a contratar. Para efectos de la presente investigación, se hará énfasis en aquellas empresas que requieren mayores solemnidades contractuales que las que implicaría una compraventa verbal. Se trata de aquellas empresas que requieren la celebración de contratos por escrito, y que, en su mayoría, son de ejecución sucesiva; verbigracia, contratos en los que el 
Formas de discriminación en el consumo, a la luz del principio de igualdad

consumidor debe ofrecer todos sus datos personales, demostrar solvencia económica y, en algunos casos, aportar información sobre su estado físico o antecedentes familiares de salud.

Dentro de las empresas que realizan estos requerimientos, se pueden incluir las que prestan servicios de salud de carácter privado, las empresas del sector financiero como las entidades bancarias y las compañías de seguros. Estas entidades, por lo general, materializan el rechazo del potencial cliente por medio de un documento, el cual viene suscrito por el gerente de la empresa, representante legal o por un jefe de área, quienes serían los facultados para celebrar contratos en nombre de la persona jurídica que representan. Esta situación hace difícil que la empresa, en caso de ser señalada como sujeto activo de discriminación, pueda esquivar su responsabilidad o pueda radicarla en cabeza de un empleado o contratista, como sucede en la discriminación como negación del acceso al establecimiento.

c) De las razones empleadas para el rechazo: En el estudio realizado se observó que, al tratarse de la abstención de celebrar contrato, el agente discriminador no realiza mayor esfuerzo por ocultar las razones del rechazo. Por el contrario, estas son manifestadas abiertamente, aunque se trate de aquellas sospechosas de discriminación, por cuanto el sujeto activo se escuda en su derecho a la libertad de contratación y autonomía privada para actuar de conformidad.

Adicionalmente, se constató que, de manera general, los empresarios en posición discriminatoria, en defensa ante la demanda de tutela impetrada, además de alegar su libertad contractual y autonomía privada como sustento legítimo de la abstención a contratar, sostuvieron que no había una violación de derechos fundamentales en su actuar, por cuanto existen otros productores o proveedores del bien o servicio requerido que podían otorgarlo, y que el cliente rechazado bien podía acudir ante ellos para la satisfacción de su necesidad.

Este argumento no fue aceptado por la Corte Constitucional, con base en la garantía de acceso equitativo de los usuarios, máxime cuando se trata de un servicio público como el bancario, o de interés público como los servicios financieros, aspectos explicados en la sentencia T-517 del 2006. La mencionada garantía de acceso equitativo consiste en el igual acceso por parte de todos los usuarios que cumplen con los requisitos que para 
tal efecto se encuentran estipulados en la Ley y los reglamentos (Corte Constitucional, T-987, 2012). Por consiguiente, un ciudadano, en pleno ejercicio de sus derechos, puede acudir ante cualquier productor o proveedor de bienes y servicios y acceder a ellos, a menos que existan razones objetivas que coarten su derecho. De no existir estas, resulta inequitativo que un ciudadano tenga que acudir a unos proveedores en vez de otros, siendo que sus semejantes pueden acudir ante cualquiera de ellos y obtener los bienes o servicios deseados.

d) De las víctimas de los actos discriminatorios: En la discriminación de consumidores como abstención a celebrar contratos, aplicarían los mismos comentarios realizados respecto de las víctimas en el aparte dedicado a la discriminación como negación del acceso al establecimiento. Nos referimos a que, cuando el rechazo de una persona coincida con la pertenencia a un grupo víctima de discriminación estructural o con una cualidad de las prohibidas para discriminar, el agente discriminador tendrá el deber de justificar suficientemente su actuación. De esto dependerá considerar la medida como discriminatoria o como un trato diferenciado.

e) De los derechos vulnerados al consumidor discriminado: En las sentencias emitidas por la Corte Constitucional que trataron el tema de la abstención de contratar, se tuteló el derecho a la igualdad siempre en compañía de otro derecho, que se consideró afectado de manera paralela por el hecho de la negación del acceso a los bienes y servicios. Por ejemplo, a través de la sentencia T- 1165 del 2001, la Corte Constitucional tuteló el derecho a la igualdad como no discriminación y el derecho a la vivienda, en conexión con el derecho a la vida en condiciones de dignidad, pues se negó la posibilidad de contratar una póliza de vida a personas portadoras de VIH, la cual era necesaria para el desembolso de un préstamo de dinero destinado a cancelar el valor de una vivienda de interés social. Por ende, la negación injustificada de la póliza de vida en razón a su condición de salud, se tradujo para los consumidores discriminados en la imposibilidad de acceder a una vivienda, necesidad que se buscaba satisfacer por medio del contrato a celebrar.

f) De las órdenes impartidas en el fallo: Los mandatos consignados en la parte resolutoria de las sentencias que tratan la abstención a contratar como acto discriminatorio, en definitiva, irrumpen la esfera de la libertad 
contractual y la autonomía privada que tanto alegan los empresarios en su defensa. Así puede observarse en la sentencia comentada en el párrafo anterior, sobre la negación de póliza de vida a personas portadoras de VIH. En ella se ordenó que, en las 48 horas posteriores a su notificación, se suscribiera, en condiciones de igualdad, la póliza requerida por los solicitantes.

La irrupción en la autonomía privada empresarial también puede verificarse en la sentencia T- 763 de 2005, en la que la Corte Constitucional ordenó a una entidad bancaria que, en el término de 10 días a partir de la notificación del fallo, realizara un nuevo estudio de riesgo crediticio, para determinar si abría una cuenta corriente a un pastor evangélico, y ordenó que no se tuviera en cuenta en dicho estudio una presunción de incapacidad de pago en virtud de la actividad económica que este realizaba.

De esta manera, se dejan planteadas las generalidades decantadas respecto a la discriminación de consumidores como negación a contratar, y se deja de manifiesto que, en nuestro Estado, la libertad empresarial del productor y proveedor no prevalece sobre los derechos fundamentales de los consumidores, como se explicará a continuación:

\section{Autonomía o libertad contractual vs Discriminación de consumidores}

Está claro que en casos de abstención de celebrar contratos se enfrentan los derechos de igualdad como no discriminación y dignidad del consumi- dor, con los derechos de libertad de contratación y autonomía privada del empresario productor/distribuidor del bien/servicio. Pues bien, se resalta que, al respecto, la Corte Constitucional ha sido enfática en sostener que en un Estado social y Constitucional de Derecho como el colombiano, prevalece la protección de los derechos fundamentales por sobre cualquier otro concepto. Por tanto, no se tendrá como una actuación constitucional el hecho de que un empresario, fundamentado en su libertad contractual y autonomía privada, discrimine a las personas impidiendo el acceso al consumo de los bienes y servicios que ofrece.

Lo anterior encuentra un sustento adicional en que la actividad se encuentra caracterizada como de interés público a nivel constitucional 
(Cont., 1991, art. 335), lo que significa que, a través de ella, se debe buscar el bien común y no sólo el beneficio patrimonial del empresario. En consecuencia, la libertad contractual de las entidades financieras se restringe cuando se enfrenta a principios y valores constitucionales, así como a la protección de derechos fundamentales, o consideraciones de interés general (Corte Constitucional de Colombia, T-517, 2006).

Vale aclarar que el empresario, en su libertad contractual, no tiene prohibido el decidir con quien contrata. Una restricción de este tipo resultaría desproporcional. Lo prohibido es emplear como criterio de diferenciación, motivos sobre los cuales no se permite discriminar y, además, realizarlo de manera injustificada, sin razones objetivas.

Cabe anotar que "la libertad de contratación, que precisamente alude al ámbito o fuero interno de la persona natural o jurídica -a su querer subjetivo-, no puede tenerse como razón objetiva" (Corte Constitucional de Colombia, T-763, 2005); es decir, la entidad financiera, o el empresario en general, no puede fundamentarse en su libertad de contratación, por no ser considerada esta una causal objetiva para su decisión. Sin embargo, factores que determinen la incapacidad de pago del solicitante del crédito o el alto peligro que puede correr el sistema financiero de otorgarse el crédito a determinado sujeto, sí podrán tenerse como razones objetivas para la abstención a celebrar contrato con un potencial cliente (Corte Constitucional de Colombia, T-763, 2005), pero se insiste, las empresas nunca deben fundamentar su decisión de no contratar en criterios sospechosos de discriminación por el simple hecho del ejercicio de su autonomía privada y libertad contractual.

\section{Conclusiones}

A partir del presente estudio se evidenció que los actos discriminatorios contra consumidores que tienen presencia en nuestro país, se manifiestan a través de formas como la aplicación de condiciones contractuales desiguales en operaciones equivalentes, la negación del acceso al establecimiento y la abstención de celebrar contrato con determinados consumidores. Del análisis realizado anteriormente, se pueden destacar los siguientes planteamientos a modo de conclusión: 
Formas de discriminación en el consumo, a la luz del principio de igualdad

El productor/proveedor del bien o servicio no está facultado, dentro de su autonomía privada, a rechazar clientes basado en prejuicios irrazonables y criterios subjetivos. Este, cada vez que aplique condiciones contractuales desiguales a unos clientes por sobre otros, está obligado a fundamentar suficientemente los factores tenidos en cuenta para las medidas adoptadas.

De no cumplir con este requisito, su actuación se tendrá como discriminatoria, por colocar en situación de desventaja a consumidores que se encuentran en igualdad de condiciones con respecto a sus semejantes.

De otra parte, cuando el rechazo de un cliente coincida con cualidades sobre las cuales se encuentra prohibido discriminar, se configura la llamada presunción de discriminación, la cual puede ser desvirtuada por el acusado de cometer el acto discriminatorio, demostrando la veracidad de las razones invocadas para su actuar, y que estas no fueron empleadas con la intención de ocultar una discriminación.

También podría desvirtuarse la presunción de discriminación probando la objetividad del estudio o del criterio sobre el cual se fundamentan las medidas adoptadas. En todo caso, de la suficiencia de la justificación que pueda ofrecer el productor/proveedor señalado de cometer el acto discriminatorio, dependerá la calificación de su actuar como una discriminación o como un trato diferenciado.

En definitiva, no se debe dejar de lado que en un Estado Constitucional como el colombiano, los derechos fundamentales siempre prevalecerán por sobre otros derechos como la libertad contractual y la autonomía privada de los empresarios, por tanto, estos últimos no podrán restringir el ingreso a los establecimientos o abstenerse de contratar de manera arbitraria invocando dicha libertad o autonomía.

Podemos afirmar, entonces, que la determinación de las formas de discriminación en el consumo resulta de vital importancia para concientizar a consumidores y empresarios sobre la ocurrencia de este tipo de actuaciones, de tal forma que estas puedan resultar de fácil detección, ya sea para tomar medidas correctivas por parte de los productores/proveedores, o para denunciar su ocurrencia por parte de los consumidores, y así lograr erradicar, finalmente, toda forma de discriminación en nuestro Estado. 


\section{Referencias}

Bernal, L., Botero, C. \& Botero, M. (2011, enero- diciembre). Análisis de las prácticas restrictivas de la competencia relacionadas con la discriminación: artículo 47 numeral 2 y artículo 50 numerales 2 y 4 del decreto 2153 de 1992. Universitas. 8. 28-55.

Concejo Distrital de Bogotá. (2013). Por el cual se ordena a establecimientos de venta y consumo de licor, con uso urbano restringido, la fijación en lugar visible de los criterios de admisión establecidos para su clientela. Proyecto de acuerdo $\mathrm{n}^{\circ} 258$ de 2013.

Congreso nacional de la República de Colombia. (12 de octubre de 2011). Por medio de la cual se expide el Estatuto del Consumidor y se dictan otras disposiciones. [Ley 1480 de 2011].

Congreso nacional de la República de Colombia. (30 de diciembre de 1992). Por el cual se reestructura la Superintendencia de Industria y Comercio y se dictan otras disposiciones. [Decreto 2153 de 1992].

Constitución Política de Colombia. [Const.]. (4 de Julio de 1991).

Convención Internacional sobre la eliminación de todas las formas de discriminación racial. (1965). Recuperada de: http://www.ohchr.org/SP/ProfessionalInterest/Pages/CERD. aspx

Corte Constitucional de Colombia. (6 de noviembre del 2001). Sentencia T- 1165 de 2001. [MP Alfredo Beltrán Sierra].

Corte Constitucional de Colombia. (18 de septiembre del 2003). Sentencia T- 808 de 2003. [MP Alfredo Beltrán Sierra].

Corte Constitucional de Colombia. (21 de julio del 2005). Sentencia T- 763 de 2005. [MP Marco Gerardo Monroy Cabra].

Corte Constitucional de Colombia. (26 de octubre del 2005). Sentencia T- 1090 de 2005. [MP Clara Inés Vargas Hernández].

Corte Constitucional de Colombia. (23 de febrero del 2006). Sentencia T- 131 de 2006. [MP Alfredo Beltrán Sierra].

Corte Constitucional de Colombia. (7 de julio del 2006). Sentencia T- 517 de 2006. [MP Marco Gerardo Monroy Cabra].

Corte Constitucional de Colombia. (1 de diciembre del 2011). Sentencia T- 909 de 2011. [MP Juan Carlos Henao Pérez].

Corte Constitucional de Colombia. (23 de noviembre del 2012). Sentencia T- 987 de 2012. [MP Luis Ernesto Vargas Silva]. 
Corte Constitucional de Colombia. (27 de marzo del 2015). Sentencia T- 141 de 2015. [MP María Victoria Calle Correa].

Díaz de Valdés, J. (abril, 2015). La igualdad constitucional. Múltiple y compleja. Revista Chilena de Derecho. 42(1). 153-187.

Porfirio Carpio, L. (2002). La discriminación de consumidores como acto de competencia desleal. Madrid: Marcial Pons. Ediciones jurídicas y sociales.

Saba, R. (2008). Igualdad, Clases y Clasificaciones: ¿Qué es lo sospechoso de las categorías sospechosas? En Teoría y Crítica del Derecho Constitucional, Tomo II. Buenos Aires: Abeledo Perrot.

Superintendencia de Industria y comercio (18 de agosto de 2010). Resolución 42828 de 2010.

Superintendencia de Industria y comercio (11 de febrero de 2002). Resolución 04285 de 2012.

Tribunal de Justicia Unión Europea, (1 de marzo de 2011). Sentencia Test Achast. 